\title{
PEMANFAATAN TOOLS ANIMASI UNTUK MEDIA PEMBELAJARAN BAGI SMKN 1 LABANG BANGKALAN MADURA
}

\section{THE UTILIZATION OF ANIMATION TOOLS AS LEARNING MEDIA FOR SMKN 1 LABANG BANGKALAN MADURA}

\author{
${ }^{1)}$ Arik Kurniawati, ${ }^{2)}$ Indah Agustien Siradjuddin, ${ }^{3)}$ Mochammad Kautsar Sophan, ${ }^{4)}$ Ariesta \\ Kartika Sari, ${ }^{5}$ Puji Rahayu Ningsih, ${ }^{6}$ Wanda Ramansyah \\ ${ }^{1,2,3)}$ Teknik Informatika, Fakultas Teknik, Universitas Trunojoyo Madura \\ ${ }^{4,5,6)}$ Pendidikan Teknik Informatika, Fakultas Ilmu Pendidikan, Universitas Trunojoyo Madura \\ *Email Korespondensi: arik.kurniawati@trunojoyo.ac.id
}

\begin{abstract}
ABSTRAK
Media pembelajaran merupakan salah satu aspek terpenting dalam proses pembelajaran, karena akan membantu siswa dalam memahami ceramah yang diberikan oleh guru. Seiring tumbuhnya teknologi informasi di Era Industrial 4.0, maka sebaiknya media pembelajaran yang digunakan juga menggunakan teknologi informasi terbaru yang dibuat semenarik mungkin sehingga menimbulkan semangat siswa dalam memperhatikan dan memahami mata pelajaran yang diajarkan. Dalam pengabdian ini, digunakan Animaker, sebagai tools untuk membuat media pembelajaran, karena memiliki banyak fitur, selain itu media ini dapat dilihat dan dipelajari oleh siswa kapan saja, di mana saja dengan smartphone yang mereka miliki. Pemanfaatan tools Animasi sebagai Media Pembelajaran dilakukan di SMKN 1 Labang, Bangkalan, Madura. Ada empat langkah utama untuk membangun media pembelajaran menggunakan Animaker, yaitu menentukan topik ceramah; memilih karakter yang sesuai dan juga property; mendefinisikan adegan; dan langkah terakhir adalah mendesain scene. Bentuk kegiatan ini adalah pelatihan tentang cara membuat media pembelajaran menggunakan Animaker dan selanjutnya adalah pendampingan dalam mengerjakan tugas untuk membuat projek sesuai dengan mata pelajaran yang meraka ajarkan. Berdasarkan pelatihan dan tugas proyek yang diberikan ini, Animaker dapat digunakan sebagai tools yang menarik untuk membuat media pembelajaran.
\end{abstract}

Kata kunci: Era Industrial 4.0; Media Pembelajaran; Animasi; Smartphone

\section{ABSTRACT}

Learning media is the most important aspect of the learning process since it will help the students understand the lectures that the teachers give. As the growth of the information technology in Industry 4.0, the learning media used should be the newest information technology that is made as interesting as possible to develop students' attention and understanding in the lectures. Animaker is used in this service as a tool to make a learning media since it has many features. Besides, this media can be seen and studied by the students anytime and anywhere using their smartphones. The utilization of animation tool as learning media is done in SMKN 1 Labang, Bangkalan, Madura. There are four main steps to make a learning media using Animaker, such as: determining the topic of the lectures, selecting the suitable character and as well as the property, defining the scenes, and the last step is designing the scenes. The form of this activity is training on making a learning media using Animaker continued by assistance in doing the assignment to make projects according to the subjects they teach. Based on the training and project assignment, Animaker can be used as an interesting tool to create the learning media.

Keywords: Industrial 4.0; Instructional Media; Animation; Smartphone

Submitted : 20 Februari 2020 Revision : 21 Februari 2021 Accepted : 21 Maret 2021 


\section{PENDAHULUAN}

Perkembangan dan kemajuan teknologi informasi berjalan sangat cepat, saat ini telah memasuki Era Teknologi Revolusi Industri 4.0, dimana teknologi internet mempunyai pengaruh yang sangat besar terhadap berbagai hal (Ristekdikti, 2018). Bahkan dalam dunia pendidikan di Indonesia, sudah saatnya memanfaatkan teknologi informasi tersebut. Teknologi informasi ini akan memberikan nilai tambah dalam proses pembelajaran. Dalam rangka meningkatkan kualitas keterampilan sumber daya manusia dengan teknologi digital agar bisa menjadi tenaga kerja yang handal sebagai pendorong Industri agar mencapai daya saing dan produktivitas tinggi, maka sekolah dan para pengajar (guru) juga memiliki peran yang penting. Para pengajar yang bertugas menyiapkan sarana media pembelajaran yang menyenangkan bisa membuat para siswa menjadi tekun dan semangat dalam belajar. Namun demikian, ternyata tidak semua sekolah siap dalam menyongsong era revolusi 4.0 ini. Masih banyak sekolah yang masih menggunakan cara pembelajaran konvesional, yakni ceramah, diskusi dan tanya jawab. Hal ini lebih dikarenakan faktor ketersediaan sarana dan prasarana sekolah yang minim serta ketrampilan para pengajar yang masih belum banyak memanfaatkan media teknologi informasi. Padahal sekolah adalah salah satu institusi yang diharapkan dapat menghasilkan sumber daya manusia yang sangat berkualitas.

SMKN 1 Labang Bangkalan adalah mitra pengabdian dalam kegiatan ini, dengan permasalahan pembelajaran masih banyak yang menggunakan metode ceramah dengan menggunakan media power point. Hal ini menyebabkan siswa kurang paham serta tidak bisa melihat dengan secara nyata dalam wujud praktik langsung padahal komponen utama dari sekolah kejuruan adalah ketrampilan. Penggunaan buku teks atau modul yang biasabiasa saja kurang dapat meningkatkan motivasi dan daya tarik siswa terhadap materi pembelajaran. Walaupun keterbatasan sarana dan prasarana peralatan untuk pembelajaran di sekolah, tapi kebanyakan siswa memiliki smartphone berbasis Android ini yang belum termanfaatkan secara maksimal dalam proses belajar mengajar.

Tujuan dari kegiatan pengabdian ini adalah pelatihan dan pendampingan pemanfaatan toos animasi Animaker untuk media pembelajaran merupakan salah satu solusi untuk peningkatan metode pembelajaran menuju Era Revolusi 4.0 yang berbasis teknologi dan pemanfaatan media smartphone guru dan siswa, sehingga keterbatasan sarana yang dimiliki sekolah tidak menjadi penghalang dalam pembelajaran untuk kegiatan produktif .

Media pembelajaran dengan menggunakan animasi sangatlah diminati oleh para siswa, karena menarik secara visual, mudah dimengerti, dan dapat diakses kapan saja. Bahkan animasi ini dapat meningkatkan motivasi belajar siswa (Sukiyasa dkk., 2013), (Alannasir, 2016), dan saat ini dikembangkan beberapa media ajar dengan menggunakan animasi, seperti ruang guru (Gideon,2018).

\section{METODE}

Pelatihan ini merupakan salah satu kegiatan pengabdian masyarakat Universitas Trunojoyo Madura dalam hibah Program Kemitraan Masyarakat yang didanai oleh DRPM Menristek Dikti. Kegiatan ini adalah workshop 1 hari dan dilanjutkan dengan pendampingan secara berkelompok untuk membuat projek pembuatan media ajar sesuai dengan mata pelajaran yang diajarkan. Peserta pelatihan adalah 15 orang guru SMKN 1 Labang Bangkalan dari berbagai mata pelajaran. Secara umum bentuk dari kegiatan ini seperti yang diilustrasikan pada Gambar 1. 


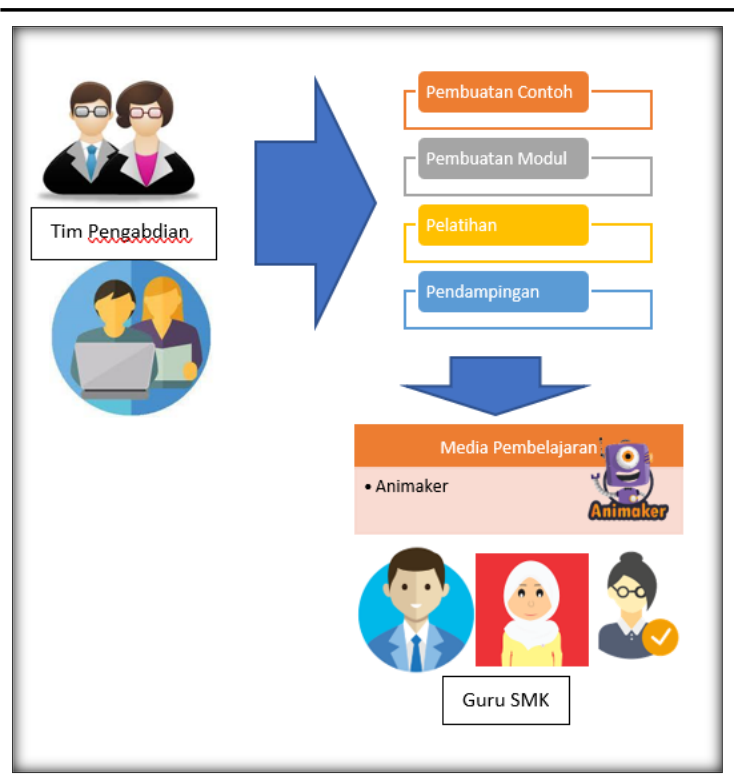

Gambar 1. Tahapan pengabdian

\section{Pembuatan Contoh}

Dalam tahapan ini, contoh animasi yang telah dibuat adalah sub materi dalam pelajaran Bahasa Inggris, yaitu 'preposition'. Seringkali siswa susah untuk membedakan penggunaan in, on, at, dan lain-lain. Dengan ilustrasi animasi diharapkan siswa dapat membedakan penggunaan masing-masing kata depan, lebih menyenangkan untuk belajar, serta materi tersebut bisa dilihat berulangulang di media smartphone milik siswa. Contoh, animasi untuk preposition ini, dapat dilihat pada Gambar 2.

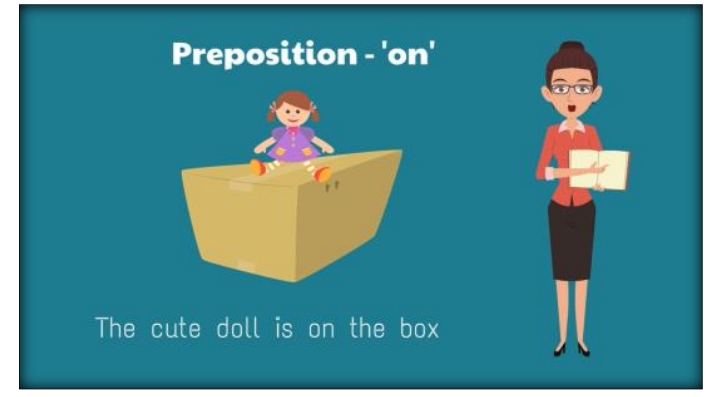

Gambar 2. Potongan animasi untuk sub pokok bahasan 'preposition'

\section{Pembuatan Modul Pelatihan}

Tools Animasi yang digunakan untuk pembuatan media pembelajaran pada kegiatan pengabdian ini adalah Tools Animaker, https://www.animaker.com/. Tools ini sangat mudah untuk dipelajari, memiliki banyak fitur, template, dan video pembelajaran yang dihasilkan dapat langsung diupload ke Youtube, dan diakses secara bebas oleh siswa sekolah, ataupun oleh pengguna lain.

Terdapat empat tahapan utama yang harus dilakukan untuk pembuatan animasi dengan tools Animaker ini, antara lain :

1) Penentuan tema materi dalam media pembelajaran

2) Penentuan karakter dan property yang ingin digunakan

3) Penentuan scene

4) Animasikan semua karakter ataupun property dalam setiap scene

Pada umumnya, materi yang dibuat animasi adalah sub materi yang sulit dipahami oleh siswa, sehingga tidak perlu semua sub materi dituangkan dalam bentuk animasi. Dengan visualisasi media ajar berupa animasi, diharapkan materi yang sulit dipahami oleh siswa menjadi lebih mudah untuk dimengerti, dan dipahami.

Tiga aset utama dalam pembuatan suatu animasi adalah karakter, property, dan yang terakhir adalah latar belakang. Aset-aset ini telah disediakan oleh Animaker dalam berbagai tema, bentuk, maupun warna. Untuk karakter maupun property, Animaker juga menyediakan expression ataupun action, sehingga animasi yang dihasilkan menjadi lebih menarik. Contoh expression maupun action dari sebuah karakter, dapat dilihat pada Gambar 3.

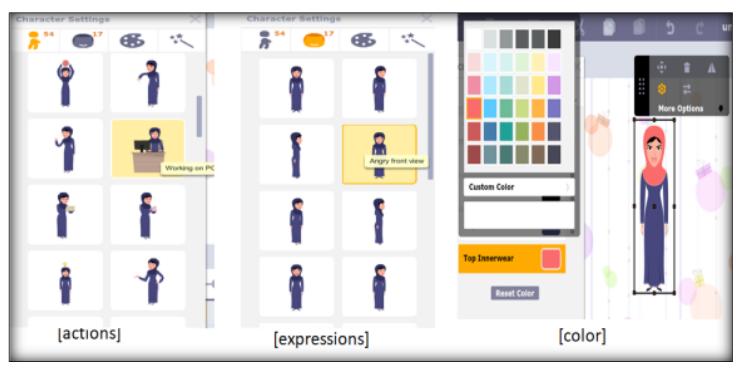

Gambar 3. Karakter yang dilengkapi dengan expression dan actions

Selain karakter ataupun property, maka asset yang terakhir adalah latar belakang. Latar belakang ini dapat membangun suasana di dalam animasi yang akan dibuat. Contoh penambahan latar belakang ini dapat dilihat pada Gambar 4 . Pada gambar tersebut, terdapat beberapa 
lemari, gambar peta, dan karpet, yang kesemuanya merupakan bagian dari background, sehingga animasi dapat menyerupai suasana asli, yaitu ruang belajar.

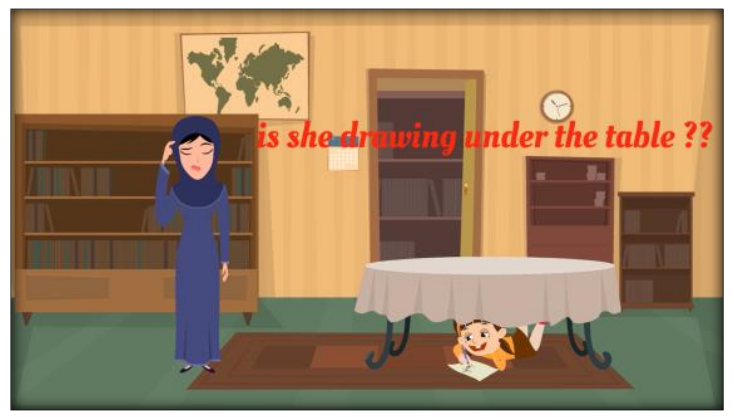

Gambar 4. Penambahan background pada animasi

Selain menggunakan asset yang telah disediakan secara bebas, Animaker juga menyediakan fitur agar pembuat animasi dapat menggunakan asset yang telah dibuat sendiri. Dengan hal tersebut, pembuat animasi dapat menyisipkan ciri-ciri khusus di dalam animasi yang dibuat.

Tahap ketiga dari pembuatan animasi, adalah penentuan scene. Di dalam scene ini akan terdapat satu atau lebih asset (kecuali background), dimana scene-scene yang telah dibuat, akan disatukan, dan menjadi satu file animasi yang utuh. Scene pertama dalam media ajar adalah perkenalan ataupun penyampaian sub materi yang akan dibahas, scene terakhir, pada umumnya diisi dengan kesimpulan, ataupun motivasi. Konten dari sub materi dapat diletakkan antara scene pertama sampai dengan scene terakhir. Contoh scene pertama dan terakhir dari suatu animasi pembelajaran, dapat dilihat pada Gambar 5.

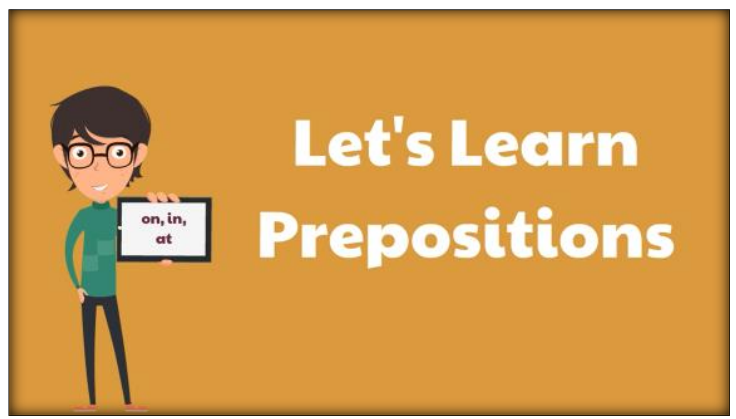

(a)

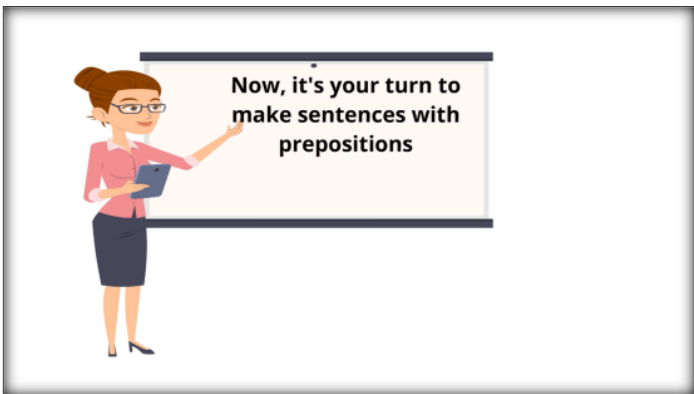

(b)

Gambar 5. Contoh scene pertama (a) dan terakhir (b) dari suatu animasi

Tahapan terakhir dalam pembuatan animasi dengan Animaker ini adalah menganimasikan semua asset yang sudah dibuat dan diletakkan dalam setiap scene. Animasi ini dapat dilakukan dengan cara membuat gerakan, mengatur time line muncul dan berakhirnya suatu asset, mengatur perubahan actions ataupun expressions pada setiap asset, dan mengatur waktu ataupun cara memunculkan suatu asset, seperti yang ditunjukkan pada Gambar 6. Pada gambar tersebut, asset berupa karakter boneka dimunculkan dengan menambahkan animasi 'sebuah tangan', sehingga animasi akan menjadi lebih menarik.

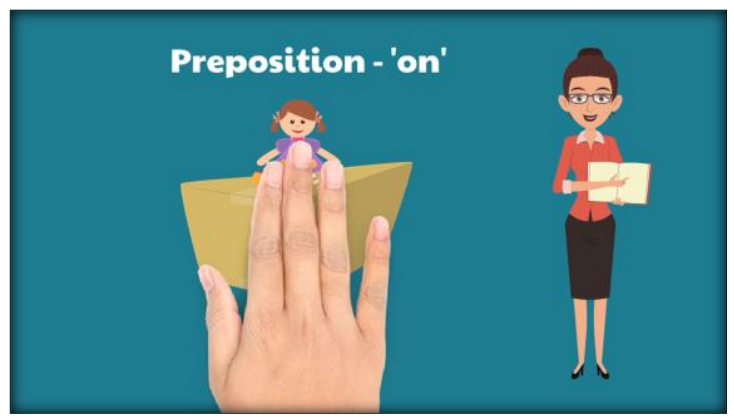

Gambar 6. Penambahan animasi

\section{Pelatihan}

Kegiatan pelatihan ini dipandu oleh 1 tim ahli sebagai pemateri dan dibantu dengan 5 orang asisten yang siap membantu para peserta, dokumentasi kegiatan ditunjukan pada Gambar 7. 


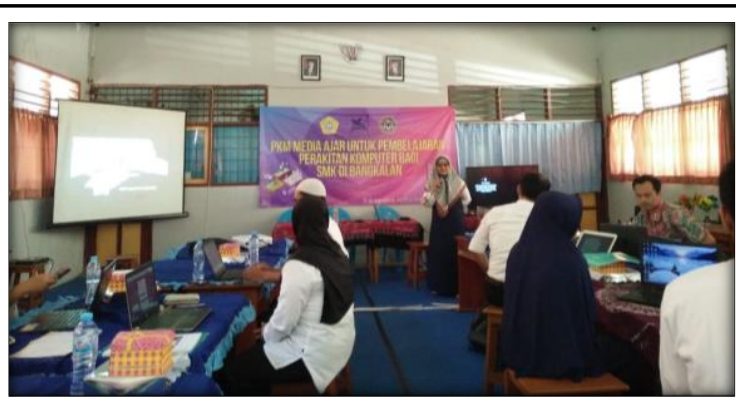

Gambar 7. Pelatihan Animaker

Metode yang diterapkan dalam pelatihan ini adalah workshop 1 hari dengan praktek secara langsung, masing-masing peserta dengan 1 laptop yang terkoneksi dengan internet, karena tools Animaker ini berbasis web yang bersifat online. Tahapan demi tahapan dijelaskan dan dipraktekan dibantu dengan modul yang membahas secara detil.

\section{Pendampingan}

Proses pendampingan dalam pembuatan media pembelajaran dilaksanakan dalam rentang waktu selama 10 hari sejak pelaksanaan workshop. Pendampingan ini dilakukan secara berkelompok, masing-masing kelompok 5 orang dengan 1 asisten. Persiapan yang harus dilakukan saat pendampingan adalah konten materi sudah dipersiapkan oleh peserta, rangcangan scenario animasi sudah digambarkan dan yang terakhir asset-aset yang diperlukan.

Hasil dari kegiatan pedampingan ini adalah media pembelajaran yang berbasis animasi dan telah diupload ke dalam Youtube, antara lain :

1. https://youtu.be/5gve1jSrqeA, materi Topologi Jaringan

2. https://youtu.be/338brRtr0Fw, materi Dasar Elektronika

3. https://youtu.be/eeP3tYEfmLs, pengenalan HTML

Gambar 8 berikut ini adalah hasil projek yang telah dibuat oleh guru SMKN 1 Labang Bangkalan.
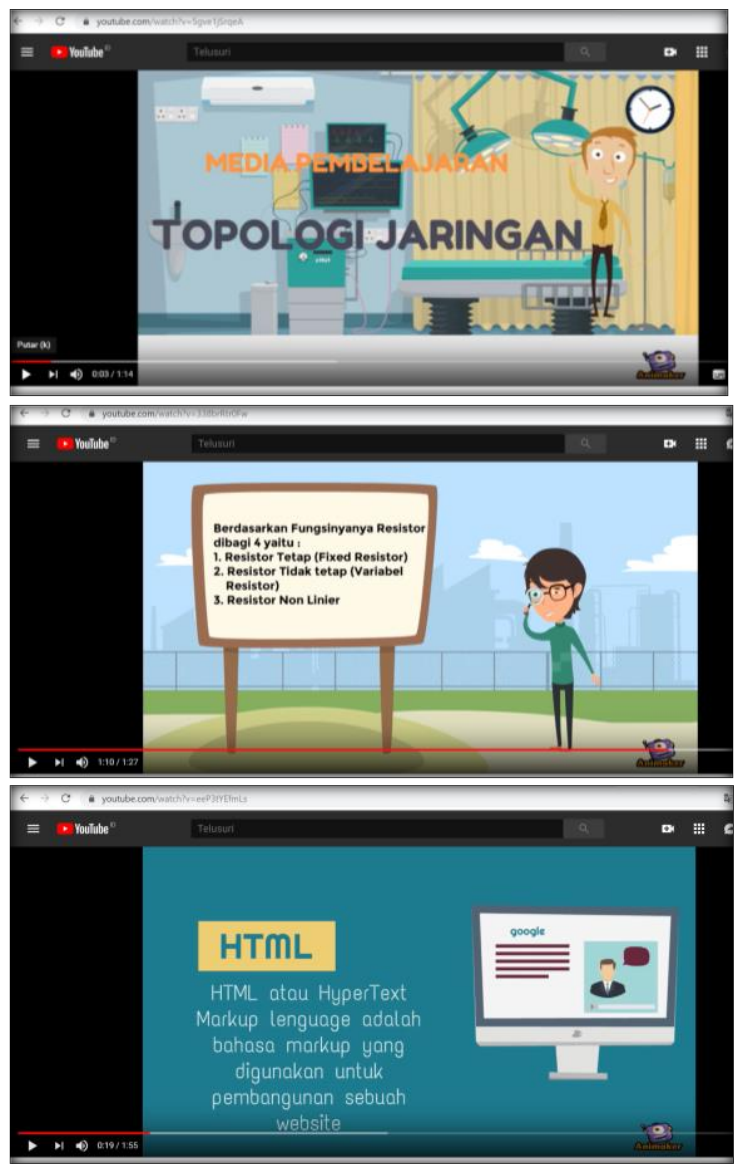

Gambar 8. Projek Media Pembelajaran berbasis animasi

\section{HASIL DAN PEMBAHASAN}

Kegiatan pengabdian pelatihan dan pendampingan pemanfaatan tools animasi Animaker untuk media pembelajaran ini dilakukan di SMKN 1 Labang, Bangkalan, Madura. Pelatihan dan pendampingan dilakukan agar para guru pada SMKN tersebut dapat membuat media pembelajaran yang lebih menarik, dan membuat siswa menjadi lebih memahami materi dan termotivasi untuk belajar.

Pada akhir kegiatan, para peserta diminta untuk mengisi kuesionar sebagai bentuk evaluasi dalam kegiatan ini. Isi dalam kuesioner ini adalah :

1. Ketertarikan peserta terhadap Animaker untuk pembuatan media ajar

2. Kemudahan penggunaan Animaker untuk membuat media ajar

3. Kebermanfaatan Animaker terhadap proses pembelajaran 
Arik Kurniawati, Indah Agustien Siradjuddin, Mochammad Kautsar Sophan, Ariesta Kartika Sari, Puji Rahayu Ningsih, Wanda Ramansyah Pemanfaatan Tools Animasi Untuk Media Pembelajaran Bagi SMKN 1 Labang Bangkalan Madura

Hasil kuesioner ini, dapat dilihat pada Gambar 9.

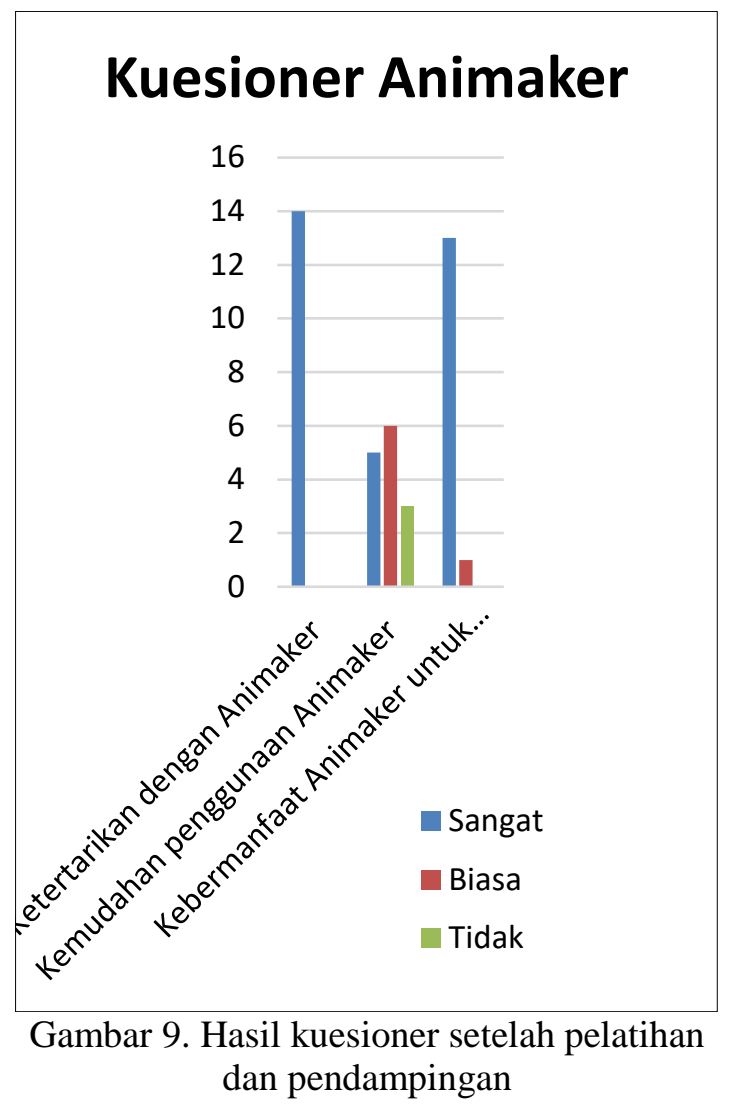

\section{SIMPULAN}

Berdasarkan kegiatan pelatihan dan pendampingan yang telah dilakukan dapat disimpulkan bahwa mitra pengabdian sangat membutuhkan pengetahuan dan ketrampilan IT untuk mendukung proses kegiatan belajar mengajar dalam mempersiapkan era Revolusi Industri. Berdasarkan hasil kuisioner kegiatan pengabdian, para peserta merasa sangat tertarik untuk membuat media pembelajaran berbasis animasi menggunakan Animaker karena tools ini sangat bermanfaat dalam proses kegiatan belajar mengajar. Beberapa peserta masih merasa kesulitan dalam penggunaan tooks tersebut.

\section{UCAPAN TERIMA KASIH}

Kegiatan pengabdian ini adalah hibah dalam Program Kemitraan Masyarakat yang didanai oleh DRPM Menristek Dikti tahun 2019.

\section{DAFTAR PUSTAKA}

Alannasir W. 2016. "Pengaruh Penggunaan Media Animasi Dalam Pembelajaran Ips Terhadap Motivasi Belajar Siswa Kelas Iv Sd Negeri Mannuruki, Journal of Educational Science and Technology, vol. 2, no. 2, p. 81

Animaker, https://www.animaker.com/

Gideon S. 2018. Peran Media Bimbingan Belajar Online 'Ruangguru' Dalam Pembelajaran Ipa Bagi Siswa Smp Dan Sma Masa Kini: Sebuah Pengantar, Jurnal Dinamika Pendidikan

Ristekdikti, 2018. Era Revolusi Industri 4.0, Saatnya Generasi Millennial Menjadi Dosen Masa Depan” 30 Januari 2018 (Daring), Tersedia pada : http://sumberdaya.ristekdikti.go.id/index. php/2018/01/30/era-revolusi-industri-40saatnya-generasi-millennial-menjadidosen-masa-depan/

Sukiyasa K, Sukoco. 2013. Pengaruh media animasi terhadap hasil belajar dan motivasi belajar siswa materi sistem kelistrikan otomotif, Jurnal Pendidikan Vokasi Vol 3, No 1 